\title{
EMC performance measurements for professional wireless microphone systems
}

\author{
B. Auinger, P. Freidl, M. Gadringer, C. Glawan, G. Winkler OVE, W. Bösch
}

\begin{abstract}
With shrinking spectral bandwidths and more intense use of the remaining frequency areas, the importance of good electromagnetic compatibility (EMC) performance of professional wireless microphone systems, as used by broadcasters, is increasing. A wireless microphone system consists of one or more pocket or handheld transmitters and usually the same amount of receivers. Both have to be immune against disturbances, and on the other hand they should not produce interferences.

This paper deals with electromagnetic compatibility (EMC) performance tests of three analogue professional wireless microphone systems. The authors describe the complete measurement procedure using two different setups. These setups employ the pocket transmitter or the receiver as device under test (DUT). Different disturbance signals are used utilizing amplitude modulation (AM), frequency modulation (FM) or digital video broadcast-terrestrial (DVB-T). The audio quality of the transmission system is rated with the total harmonic distortion plus noise $(\mathrm{THD}+\mathrm{N})$. Additionally, the authors investigate intermodulations (third harmonic) caused by the transmitter. The results of all performance tests are extensively discussed.
\end{abstract}

Keywords: EMC performance test; professional wireless microphone systems; DVBT EMC test; EMC test setup; EMC test realization

Prüfungen der Elektromagnetischen Verträglichkeit von professionellen analogen Funkmikrofonsystemen.

Mit den kleiner werdenden verfügbaren Spektren und der intensiveren Nutzung der verbleibenden ist ein gutes EMV-Verhalten von professionellen Funkmikrofonsystemen ein immer wichtiger werdendes Kriterium. Diese Funksysteme bestehen aus einem oder mehreren Taschen- und Handsendern und der gleichen Anzahl von Empfängern und werden oft bei Fernseh- und Rundfunkanstalten eingesetzt. Beide, sowohl Sender als auch Empfänger, müssen störfest gegenüber äußeren Einflüssen sein und sollen selbst keine Störungen produzieren

Dieser Beitrag handelt von den Prüfungen der Elektromagnetischen Verträglichkeit von drei professionellen analogen Funkmikrofonsystemen. Die Autoren geben eine Einführung in die aktuelle Situation und beschreiben das komplette Messverfahren mit zwei Messaufbauten. Mit diesen Aufbauten werden jeweils der Sender oder der Empfänger getestet. Dabei werden Störsignale mit unterschiedlichen Modulationsarten, Amplitudenmodulation (AM), Frequenzmodulation (FM) und Digital Video Broadcast-Terrestrial (DVB-T) verwendet. Die Qualität des übertragenen Audiosignals wird mit dem Total Harmonic Distortion + Noise-Kriterium (THD+N) bewertet. Zusätzlich werden die Intermodulations-Störungen, die vom Sender unter gewissen Umständen erzeugt werden, gemessen. Die Ergebnisse der Prüfungen werden anschließend ausführlich diskutiert.

Schlüsse/wörter: Prüfung des EMV-Verhaltens; professionelle Funkmikrofon-Systeme; DVBT-EMV-Test; EMV-Test Setup; Realisierung der EMV-Prüfung

Received November 9, 2015, accepted January 5, 2016, published online February 1, 2016

(c) The Author(s) 2016. This article is published with open access at Springerlink.com

\section{Introduction}

Wireless microphone systems are a vital part in today's production practices, in theaters as well as in broadcast environments. Because of their ease of setup and simple operation they are employed from simple one-channel events up to very complex setups, where hundred and even more high quality transmission channels have to share the available radio frequency (RF) spectrum with other operational RF services, e.g. for coordinating stage managers, or in-earmonitoring systems [1-3]

A wireless microphone transmission system consists of

- The RF transmitter which is typically a hand-held transmitter with a fixed or exchangable microphone capsule in a handy housing, or a body pack transmitter with a headset microphone connected by a cable.

- An antenna system consisting of active or passive antennas of different type (quasi-omnidirectional or log-periodic), using am- plifiers with fixed or variable gain. Some antenna models are equipped with automatic gain adjustment, performed by the RF receiver. Antennas can be equipped with bandpass filters to reject noise from external RF interferers.

\footnotetext{
Auinger, Bernhard, Institute of Electronics, Graz University of Technology, Inffeldgasse 12/l, 8010 Graz, Austria (E-mail: bernhard.auinger@tugraz.at); Freidl, Philipp, Institute of Microwave and Photonic Engineering, Graz University of Technology, Inffeldgasse 12/1 8010 Graz, Austria (E-mail: philipp.freidl@tugraz.at); Gadringer, Michael, Institute of Microwave and Photonic Engineering, Graz University of Technology, Inffeldgasse 12/I, 8010 Graz, Austria (E-mail: michael.gadringer@tugraz.at); Glawan, Christian, Broadcast Engineering Planning and Design, Austrian Broadcasting Cooperation (ORF), Vienna, Austria (E-mail: christian.glawan@orf.at); Winkler, Gunter, Institute of Electronics, Graz University of Technology, Inffeldgasse 12//, 8010 Graz, Austria (E-mail: gunter.winkler@tugraz.at); Bösch, Wolfgang, Institute of Microwave and Photonic Engineering, Graz University of Technology, Inffeldgasse 12/l, 8010 Graz, Austria (E-mail: wbosch@tugraz.at)
} 
- Connections between the antenna(s) and the transmitting or receiving device using coaxial cables with a typical impedance of $50 \Omega$. If more receiver units are in use, an antenna signal distribution system using active or passive combiners can be employed.

- The RF receiver, which often is a stationary, rack mount unit. The received audio signal is typically transferred to the sound mixer by symmetric cables in an analog or digital domain.

The requirements for the high quality transmission systems are

- Broadcast sound quality, i.e. an audio signal frequency range of at least $15 \mathrm{kHz}$ at typically smaller than $1 \%$ total harmonic distortion (THD) and a signal-to-noise-ratio (SNR) of $96 \mathrm{~dB}$ or more.

- Low latency time with a maximum of $4 \mathrm{~ms}$ between an acoustic event captured by the microphone and the electrical representation thereof at the receiver. For in ear monitoring low latency is vital, otherwise the artist would be irritated by flanging and phasing effects.

- High robustness in the whole RF coverage field against interferences.

- High spectral efficiency for the ever-growing amount of channels needed.

- Small size and light-weight transmitters, long battery life with a minimum of 6 hours.

- The regulation requires $50 \mathrm{~mW}$ maximum effective radiated power (ERP) and a maximal allocated bandwidth of $200 \mathrm{kHz}$ in the ultra high frequency (UHF) range [4].

Currently available high-end wireless microphone systems are using the spectrum between $470 \mathrm{MHz}$ and $790 \mathrm{MHz}$. The microphone systems are secondary service in this frequency spectrum range, in comparison to the primary service digital video broadcastterrestrial (DVB-T). They are using either analog frequency modulation (FM) or digital modulation principles. The FM employs typically $\pm 50 \mathrm{kHz}$ nominal deviation and vendor-specific compander systems to achieve the required audio performance. The digital modulation principles are also vendor specific.

With the socalled "Digital Dividend I", the regulation authorities have rededicated the frequency range between $800 \mathrm{MHz}$ and $900 \mathrm{MHz}$ from broadcast applications to long term evolution (LTE) applications [5]. This means that all the existing DVB-T transmitters were relocated into the spectrum below $800 \mathrm{MHz}$, which is now missing for wireless microphone applications.

Local Broadcasters expect that also in Austria the "Digital Dividend II" will force them to even give up the UHF spectrum between $700 \mathrm{MHz}$ and $800 \mathrm{MHz}$ [6].

A thought for solving these issues is moving complex wireless microphone applications to alternative frequency ranges like to the lower very high frequency (VHF) range or frequencies above $1 \mathrm{GHz}$. Unfortunately, this scenario is not feasible with adequate expenditure. In the first case, moving to the VHF range, antenna lengths have to increase to keep the performance. Besides that, there is lot of man-made RF noise in this frequency range. In the second case, going above $1 \mathrm{GHz}$, wireless point to point transmissions become more dependent on the line of sight (LOS) connection and the RF absorption of the moving human body is a true challenge. If multi-path scenario processing is taken into account, battery life is decreased due to an increase of energy consumption of the transmitter.

In typical setups, "true diversity" receivers with two receive (RX) antennas are employed $[7,8]$. Depending on the production environment, the placement of them for achieving optimum RF performance within the RF coverage field without disturbing the artistic vision of the production director can be demanding. Switching to higher frequencies would require to set up complex antenna arrays, which is not practicable in daily business

Since there are a few vendors that provide FM systems and also digital transmission line systems for the professional market, the Austrian Broadcasting Corporation (ORF) decided to call for a tender process, in which various systems shall be evaluated concerning usability, RF behavior as well as obtained audio performance.

This paper presents the investigations of the RF behavior which is performed in partnership with the Institute of Electronics, the Institute of Microwave and Photonic Engineering, Graz University of Technology and the Austrian Broadcasting Corporation (ORF). The tests were developed under practical considerations, scientific reproducibility of all measurements is maintained.

\section{Definition of measurement goals}

With the digital spectrums becoming tighter with "Digital Dividend I" and "Digital Dividend II", the robustness against external interferers as well as lowest possible generation of disturbances by the devices itself is demanded. To reach feasable measurement time, the authors distilled the following tests to verify, if the upper requirements are met by the tested devices. All tests are done in an RF anechoic chamber. This chamber contains a turntable and two movable horn antennas. The test setups and procedures are deducted of $[9,10]$, they use a sine signal of $1 \mathrm{kHz}$ as audio test signal for the sake of setup simplicity. They include:

(1) Verification of the influence on the pocket transmitter by an amplitude modulated (AM) RF disturbance signal with $80 \%$ modulation depth. The modulation signal is a sine with a frequency of $1.4 \mathrm{kHz}$. The RF signal has an E-field strength of $3 \mathrm{~V} / \mathrm{m}$ and will interfere on the device under test (DUT) in 5 positions and with vertical and horizontal polarization. The pocket transmitter transmits a $1 \mathrm{kHz}$ test-signal provided by the audio analyzer with an amplitude of $10 \mathrm{mV}$ RMS. The quality of the audio signal provided by the receiver output is rated with total harmonic distortion + noise $(\mathrm{THD}+\mathrm{N})$, again by the audio analyzer.

(2) Verification of the influence on a pocket transmitter by an RF signal with DVB-T modulation, vertical and horizontal polarization. The audio quality will be rated by the THD+N of the signal at the receiver. The signal at the transmitter is a sine wave with a frequency of $1 \mathrm{kHz}$ and an amplitude of $10 \mathrm{mV}$ RMS. The edges of the spectrum of the DVB-T signal are placed $600 \mathrm{kHz}$ below and above the TX frequency of the pocket transmitter. Additionally, the DVB-T signal is also directly placed on the TX-frequency (in-band disturber). The disturbance signal has an E-field strength of $3 \mathrm{~V} / \mathrm{m}$, the authors perform the tests in five positions.

(3) We measure the intermodulations of the pocket transmitter, when it is disturbed with an AM-modulated carrier $(1.4 \mathrm{kHz}$, $80 \%$ modulation depth). The disturber occurs in the frequency range between $530 \mathrm{MHz}$ and $560 \mathrm{MHz}$. The authors measure the ratio of the of transmit power of the pocket transmitter in comparison to the third order intermodulation products. The measurement is done in 5 positions and with horizontal and vertical polarization of the disturbance signal.

(4) We investigate the susceptibility performance of the receiver with a disturbance signal using AM modulated signal with $80 \%$ modulation depth, modulation signal is a sine with frequency is $1.4 \mathrm{kHz}$, the E-field strength at the DUT is $3 \mathrm{~V} / \mathrm{m}$ and vertical and horizontal polarization. Again, the $\mathrm{THD}+\mathrm{N}$ is measured with the audio analyzer. The analyzer generates an audio test signal with $10 \mathrm{mV}$ RMS amplitude and a frequency of $1 \mathrm{kHz}$. We executed the measurements in five positions. 


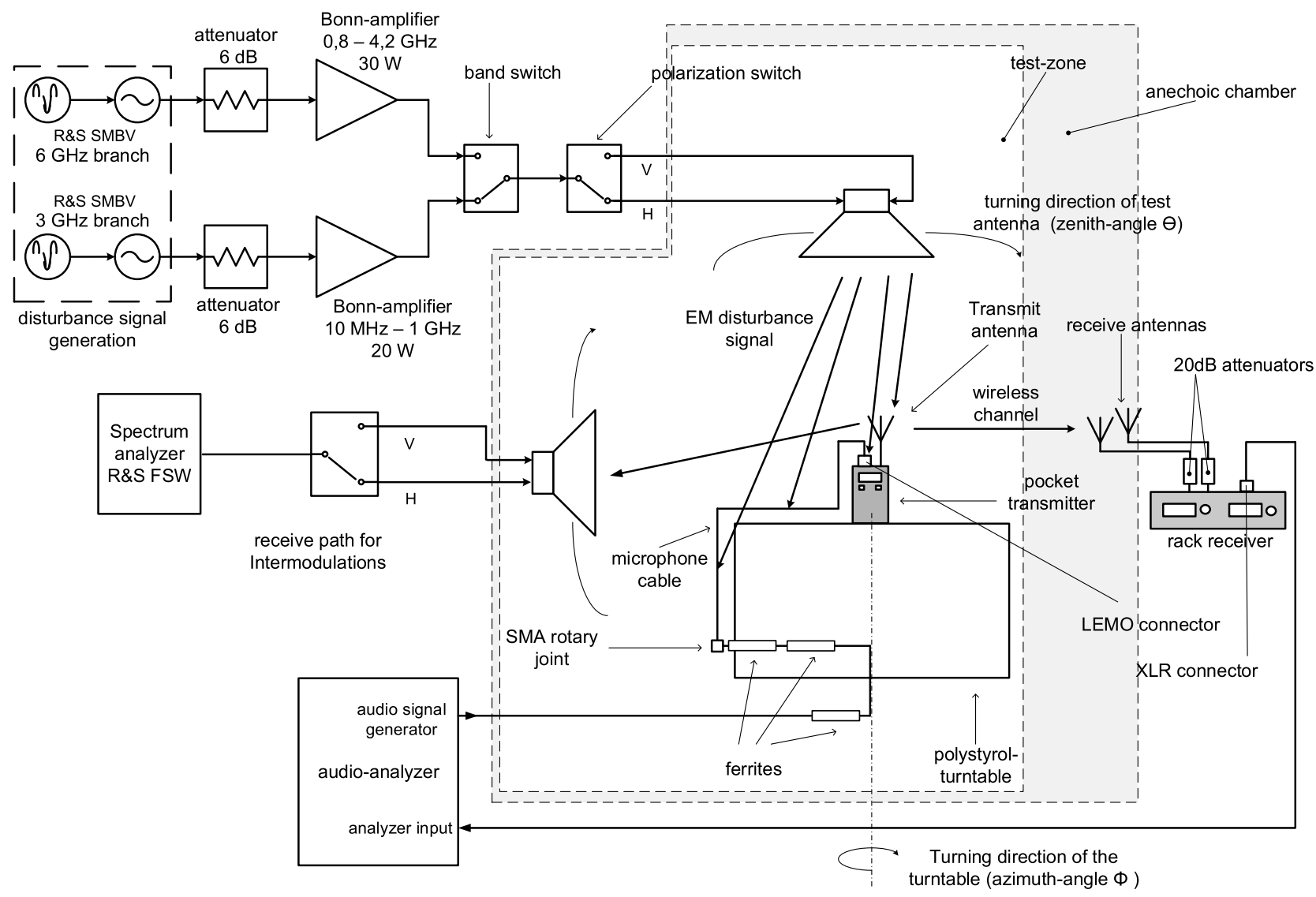

Fig. 1. Measurement setup with the handheld transmitter as DUT including receive path for intermodulation distortion measurements

Generally, the pocket transmitter is operating at a transmit frequency $544.4 \mathrm{MHz}$. The mentioned five positions are

$$
\{\Phi, \Theta\} \in\left\{0^{\circ}, 0^{\circ}\right\},\left\{0^{\circ}, 90^{\circ}\right\},\left\{90^{\circ}, 90^{\circ}\right\},\left\{180^{\circ}, 90^{\circ}\right\},\left\{270^{\circ}, 90^{\circ}\right\}
$$

in a spherical coordinate system, where $\Theta$ is the zenith angle and $\Phi$ is the azimuth angle. The north pole is at $\Phi=0^{\circ}, \Theta=0^{\circ}$.

\section{Measurement setup}

For the electromagnetic compatibility (EMC) performance tests of the pocket transmitter the setup depicted in Fig. 1 is used. The authors do the EMC tests of the receiver with the setup in Fig. 2. Both setups are extensively discussed in the this section.

The setup in Fig. 1 uses the pocket transmitter as device under test. The disturbance signal is generated with the "disturbance signal generation block". The $6 \mathrm{~dB}$ attenuators minimize the influence of the amplifier input impedance on the signal generators. The disturbance signal is amplified and radiated by the test antenna. The polarizations can be switched with RF relays. The disturbance E-field impinging on the DUT and its cables can cause malfunction of the device.

The pocket transmitter is placed on the turn-table in the middle of the quiet zone. The quiet zone is a certain volume in the anechoic chamber, where the still existing reflections are below a defined level. The receive antennas are placed close to the corners of the anechoic chamber, they are outside the disturbance signal influence. The antennas are connected to the receiver using attenuators of $20 \mathrm{~dB}$. The receiver is located outside the anechoic chamber. The attenuators allow the transmission system to work without overload of the RF frontend of the receiver.
We use log-periodic antennas for all tests with the pocket transmitters, and rod antennas for the receiver tests. The test antenna can be turned in the $\Theta$ (zenith) plane and the table can be turned in the $\Phi$ (azimuth) plane.

The audio analyzer generates the audio test tone, which is a sine wave with a frequency of $1 \mathrm{kHz}$ and an amplitude of $10 \mathrm{mV}$ RMS. This signal is fed to the pocket transmitter over a coaxial cable with ferrites. These ferrites minimize the influence of the cable on the DUT. A rotary joint in the table conducts the signal to a cable that simulates the microphone cable between the microphone capsule and the transmitter. This cable is part of the DUT, as it acts as a parasitic antenna. The audio analyzer determines the THD+N of the audio signal delivered the receiver output. The pocket transmitters and the receiver settings are set to reach an audio level of $0.556 \mathrm{~V}$ RMS. This guarantees equal conditions for all DUTs.

In case of intermodulation distortion measurements are executed, the second test antenna receives the transmitted signal and the intermodulations produced by the transmitter. The polarizations of the receiving test antenna can be horizontal and vertical.

The setup in Fig. 2 works the same way as the setup in Fig. 1, only transmitter and receiver are exchanged. As we don't execute investigations with intermodulation with the receivers, the second test antenna for reception is not used in this case.

We investigate two frequency ranges, a coarse one from $400 \mathrm{MHz}$ to $4 \mathrm{GHz}$ with logarithmic stepping of $1 \%$ and a fine one around the TX frequency of $544.4 \mathrm{MHz}$ from $530 \mathrm{MHz} 560 \mathrm{MHz}$ with linear steps of $100 \mathrm{kHz}$.

The employed audio analyzer is the Rohde \& Schwarz UPL. It calculates the total harmonic distortion + noise in the following way, 


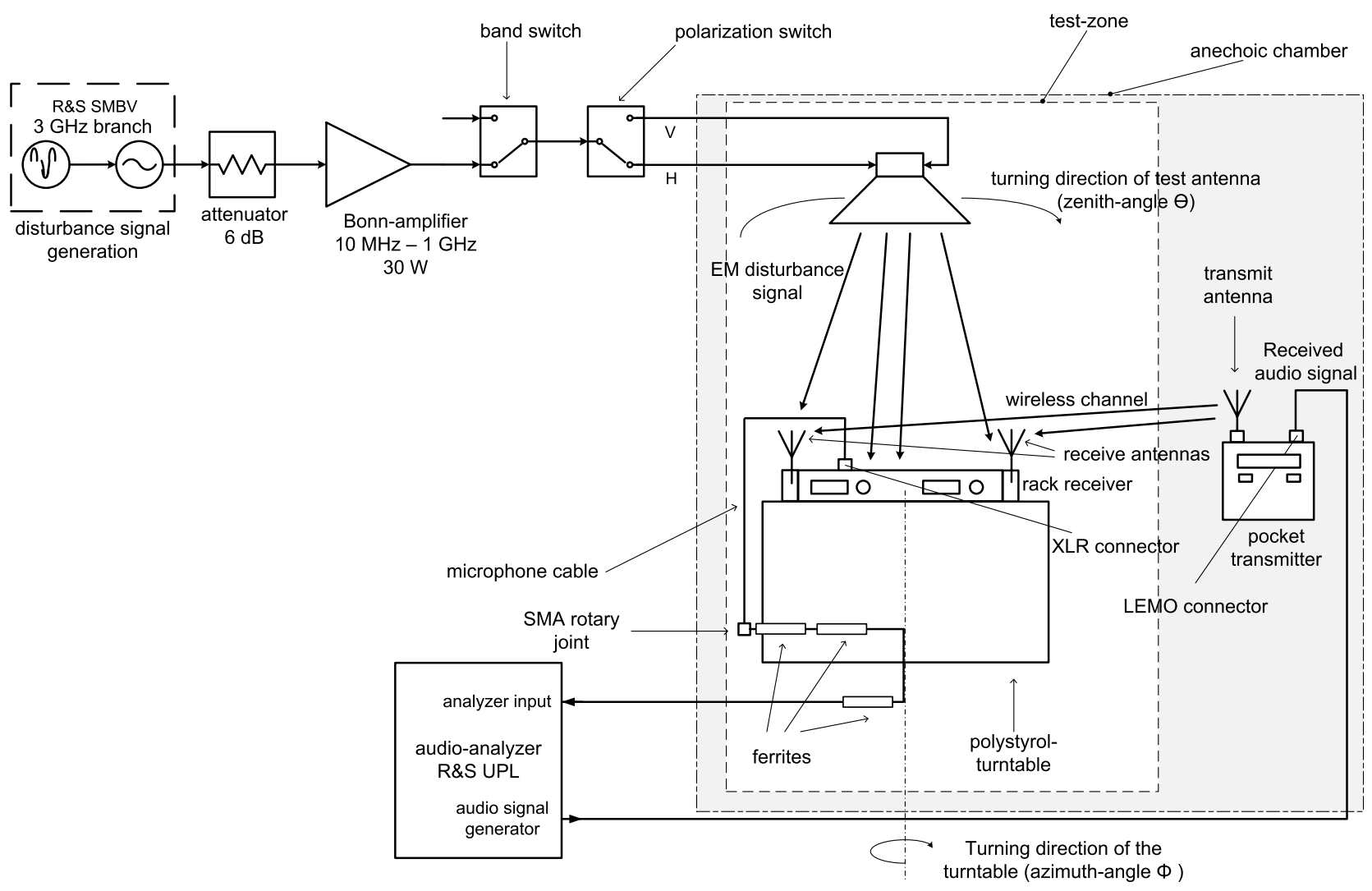

Fig. 2. Measurement setup with the receiver as DUT

where $U_{d}$ are the voltage levels of the harmonics of the sine audio test signal [11]:

$$
\mathrm{THD}+\mathrm{N}[\text { in } \%]=\frac{\sqrt{U_{\mathrm{d} 2}^{2}+U_{\mathrm{d} 3}^{2}+\cdots+U_{\text {noise }}^{2}}}{\text { total RMS value of the audio signal }}
$$

\section{Measurement results}

A important learned lesson from the practical tests is that the $\mathrm{THD}+\mathrm{N}$ is increasing very fast to an unacceptable value, as the disturbance signal power grows by e.g. $1 \mathrm{~dB}$. An audio signal with a $\mathrm{THDN}=5 \%$ is useless in the same way as if the connection is completely disrupted $\left({ }^{*} C D\right)$, both signals are unacceptable.

The influence of the $A M$ modulated disturbance signal on the pocket transmitters is depicted in Fig. 3 for the coarse frequency grid ( $400 \mathrm{MHz}$ to $4 \mathrm{GHz}$ in logarithmic stepping of $1 \%$ ) and for the fine frequency grid $(530 \mathrm{MHz}$ to $560 \mathrm{MHz})$ in Fig. 4. All three systems have different standard $\mathrm{THD}+\mathrm{N}$ values, System $\mathrm{A}$ is around $0.23 \%$, System B is around $0.12 \%$ and System C is around $0.14 \%$. All of them are well below the limit of $1 \%$, so they all fulfill the specification in the undisturbed as in the disturbed case.

System A does not show any influence, whether in fine nor in coarse frequency grid. System B show sensibilities in both grids, but still below the limit. System $C$ exhibits rises of the $T H D+N$, but not exceeding $0.2 \%$.

Figure 5 show the $I M D$ related to the $T X$ carrier power in $[\mathrm{dBc}]$ for $50 \mathrm{~mW}$ transmit power. System A has a quite stable IMD around $-38 \mathrm{dBC}$, while system $C$ has the highest IMD around $-35 \mathrm{dBC}$. System $B$ has the lowest IMD of all, below the TX frequency of $544.4 \mathrm{MHz}$ it is around $-40 \mathrm{~dB}$ and above the lower value of $-50 \mathrm{dBc}$.

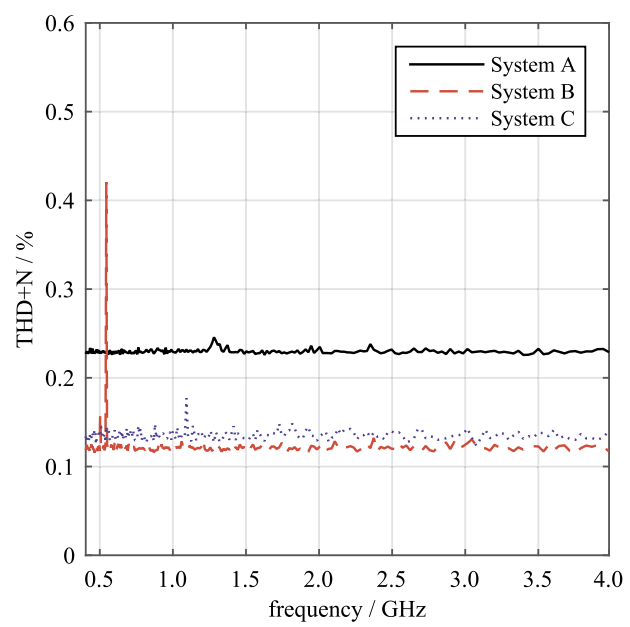

Fig. 3. Maximum $T H D+N$ versus frequency employing an $A M$ interferer with the coarse frequency grid (DUT: pocket transmitter)

The IMDs of the pocket transmitters at the lower transmit power of $10 \mathrm{~mW}$ is depicted in Fig. 6 . System $A$ has the best performance with an IMD around $-45 \mathrm{dBc}$, while system $B$ is around $-30 \mathrm{dBC}$ below the TX frequency and around the lower value of $-35 \mathrm{dBC}$ above the TX frequency. System $C$ offers two modes, Mode 1 is around $-33 \mathrm{dBC}$ and Mode 2 is around the lower value of $-38 \mathrm{dBC}$. In both modes the IMD stays on the same levels on both sides of the TX frequency. 


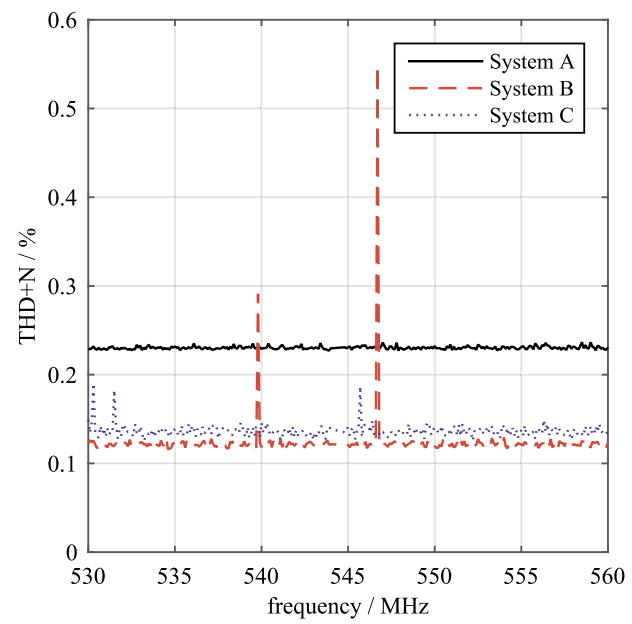

Fig. 4. Maximum THD+N versus frequency employing an AM interferer with the fine frequency grid (DUT: pocket transmitter)

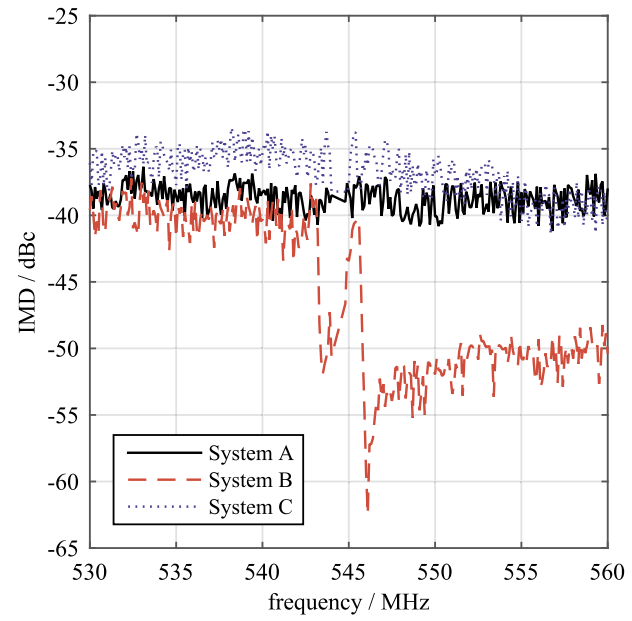

Fig. 5. Intermodulation distortion (IMD) related to the carrier versus frequency employing an AM interferer with the fine frequency grid for TX power of $50 \mathrm{~mW}$

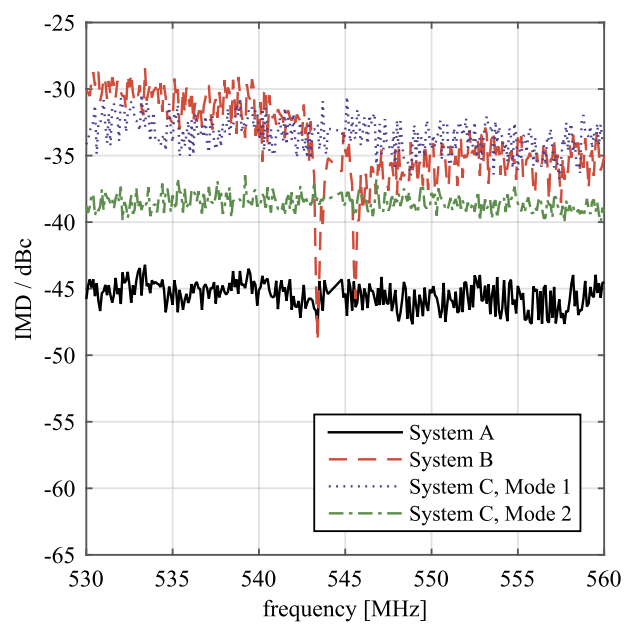

Fig. 6. Intermodulation distortion (IMD) related to the carrier versus frequency employing an $A M$ interferer with the fine frequency grid for TX power of $10 \mathrm{~mW}$

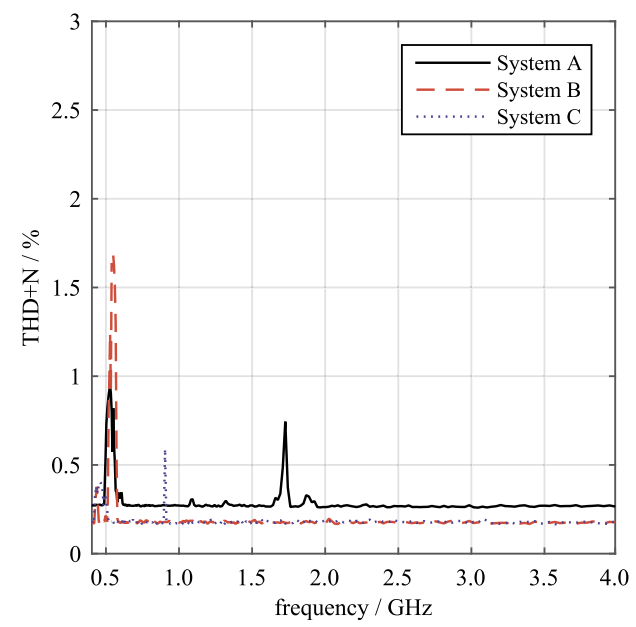

Fig. 7. Maximum THD+N versus frequency employing an $A M$ interferer with the coarse frequency grid (DUT: receiver)

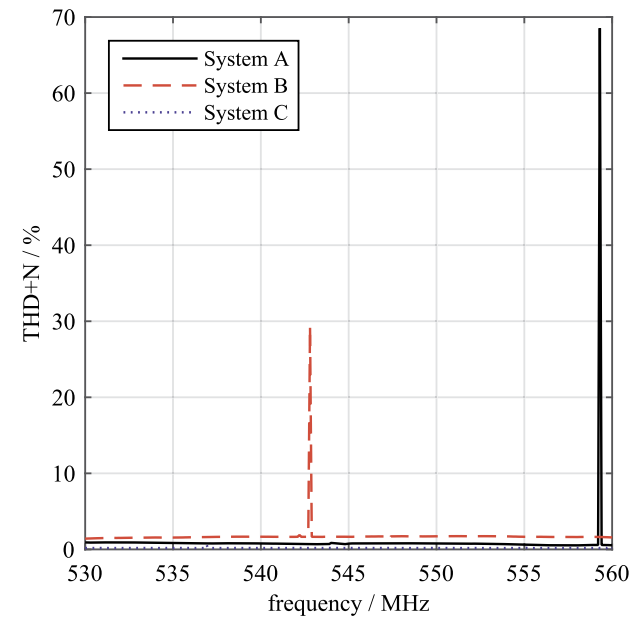

Fig. 8. Maximum THD+N versus frequency employing an AM interferer with the fine frequency grid (DUT: receiver)

The disturbance test of the receiver units is interesting, as they have proven to be more sensible than the transmitters. The disturbance signal is AM modulated, the field strength is $3 \mathrm{~V} / \mathrm{m}$. Both are tested in fine and coarse frequency grid. Figure 7 shows the $\mathrm{THD}+\mathrm{N}$ versus the coarse frequency grid. System $\mathrm{A}$ is exceeding the $\mathrm{THD}+\mathrm{N}$ limit of $1 \%$ in the TX frequency region of $544.4 \mathrm{MHz}$ and has smaller peak around $1.7 \mathrm{GHz}$. System B has an unacceptable high THD+N peak of $1.7 \%$ around $558 \mathrm{MHz}$. System $\mathrm{C}$ has a small peak of $0.6 \%$ around $900 \mathrm{MHz}$.

Figures 8 and 9 show the $T H D+N$ versus the fine frequency grid for the receiver tests with the small step size. They contain the same data but use different scaling on the $y$-axis to show the behavior in lower $\mathrm{THD}+\mathrm{N}$ regions better. These pictures reveal strong weaknesses for system B with a THD+N of $29 \%$ close to the TX frequency and for system A with a THD+N of $70 \%$ at approximately $559 \mathrm{MHz}$. System $\mathrm{C}$ has small THD+N peak at $0.6 \%$ at a frequency of $537 \mathrm{MHz}$.

The immunity measurement results of the pocket transmitter when it is disturbed with a DVB-T signal, are depicted in Table 1.

System A is always below a THD+N of $0.93 \%$, while system B has the best performance, because it is always below $0.36 \%$. Sys- 


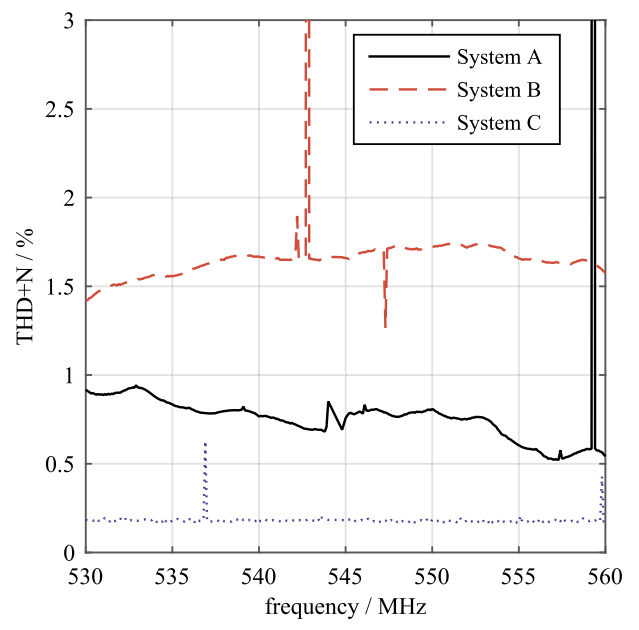

Fig. 9. Maximum THD+N versus frequency employing an AM interferer with the fine frequency grid as in Fig. 8; $y$-axis resolution changed for better readability (DUT: receiver)

Table 1. THD+N at tests using DVB-T disturbance signals

\begin{tabular}{lcll}
\hline Offset to TX carrier & $\begin{array}{l}-600 \mathrm{kHz} \\
\text { THDN (\%) }\end{array}$ & $\begin{array}{l}0 \mathrm{kHz} \\
\text { THDN (\%) }\end{array}$ & $\begin{array}{l}+600 \mathrm{kHz} \\
\text { THDN (\%) }\end{array}$ \\
\hline System A & 0.24 & 0.93 & 0.23 \\
System B & 0.12 & 0.36 & 0.12 \\
System C & 23.51 & $\mathrm{CD}^{\mathrm{a}}$ & 0.27 \\
\hline
\end{tabular}

${ }^{a}$ Connection disrupted (CD): means that no THD+N value can be measured as there is no link between the transmitter and the receiver

Table 2. THD+N and generator power level at the "'Brute Force"' tests

\begin{tabular}{llccc}
\hline & System and mode & AM & FM & DVBT \\
\hline THDN (\%) & System A & $\mathrm{CD}^{a}$ & $\mathrm{CD}^{a}$ & $\mathrm{CD}^{\mathrm{a}}$ \\
Generator-level (dBm) & & -15 & -23 & 1 \\
THD+N (\%) & System B & 10 & 10 & -0.5 \\
Generator-level (dBm) & & -15 & -10.4 & 5 \\
THD+N (\%) & System C & 20 & 30 & 10 \\
Generator-level (dBm) & & -21 & -18 & 3.77 \\
\hline
\end{tabular}

${ }^{a}$ Connection disrupted (CD): means that no THD+N value can be measured as there is no link between the transmitter and the receiver

bemark: at DVB-T tests a THD+N of $10 \%$ could not be reached with the available amplifier powers, as the system was very immune to disturbances

tem $C$ exhibits the weakest performance, because directly at the TX frequency, the connection is disrupted (CD).

The immunity measurement results of the pocket transmitter when it is disturbed inside the used transmit band ("Brute Force" test) with a disturbance signals using different modulations are depicted in Table 2. The disturber power is risen until a transmission system fails. They start to fail within small amounts of transmit power, like $0.5 \mathrm{dBm}$. Some systems immediately have disrupted connections, others have a very high $\mathrm{THD}+\mathrm{N}$. For practical usage, all these cases have the same effect, the audio signal is no longer usable and can be rated as fail.
As a simplification for the measurement, only the signal generator power levels are depicted in Table 2. Nevertheless, still a good comparability between the systems is given.

In the "brute force tests" shown in Table 2, the system A is weaker than all others with the FM disturber, as it stops the connection at lower power levels than the other systems. System $C$ is weaker than the other systems when AM disturbers are employed.

All systems are quite robust against disturbances with DVB-T modulations, system B was the most robust as a THD+N value of $10 \%$ could not even be reached with the available power amplifiers. In general, system B is the most robust of all systems in the "brute force" tests.

\section{Conclusion}

This paper reveals the strategy for electromagnetic compatibility (EMC) performance tests for professional wireless microphone systems. The authors describe the current situation of shrinking available spectrum size. Therefore it is crucial that the transmission systems are immune against disturbances and don't produce interferences influencing other systems.

The tests focus on certain scenarios, to get the maximum information on the systems in a limited time frame. We describe all tests in detail, with the used setups and disturbance signals. We discuss the results of three different analog transmission systems with their upsides and downsides. The procedures presented in this paper enable the reader to design a test system for a similar purpose and execute the EMC performance tests.

The results show that the different systems have different strong and weak sides. So the transmission system user has to choose different systems in differing disturbance scenarios.

\section{Acknowledgement}

The authors would like to thank the Austrian Broadcasting Corporation (ORF) for the support. Also we owe our gratitude to Dominik Amschl for practical measurement support.

Open Access This article is distributed under the terms of the Creative Commons Attribution 4.0 International License (http://creativecommons.org/ licenses/by/4.0/), which permits unrestricted use, distribution, and reproduction in any medium, provided you give appropriate credit to the original author(s) and the source, provide a link to the Creative Commons license, and indicate if changes were made.

\section{References}

1. Sennheiser (2013): Sennheiser beim Eurovision Song Contest 2013 in Malmoe. Press release.

2. Sennheiser (2015): ORF setzt für den Eurovision Song Contest auf Sennheiser. Press release.

3. AKG (2015): Life ball Vienna 2015 powered by AKG. Press release.

4. Bundesministerium für Verkehr, Innovation und Technologie (1999): Funk-Schnittstellenbeschreibung, Ton- und Bildübertragung. Vienna.

5. Wikipedia (2015): Digitale dividende, https://de.wikipedia.org/wiki/Digitale_Dividende.

6. Wikipedia (2015): Digitale dividende II, https://de.wikipedia.org/wiki/Digitale_ Dividende_II.

7. Sigismondi, G., Tapia, C. (2008): Wireless systems guide—antenna setup. Shure Educational Publication

8. Audio-Technica (2003): $4000 \& 5000$ series, professional UHF wireless systems, installation and operation.

9. Harmonized European Standard, ETSI EN 301 489-1 V1.9.2 (2011): Electromagnetic compatibility and radio spectrum matters (ERM); electromagnetic compatibility (EMC) standard for radio equipment and services; part 1: common technical requirements, 2011-09.

10. Harmonized European Standard, ETSI EN 301 489-9 V1.4.1 (2007): Electromagnetic compatibility and radio spectrum matters (ERM); electromagnetic compatibility (EMC) standard for radio equipment and services; part 9: specific conditions for wireless microphones, similar Radio Frequency (RF) audio link equipment, cordless audio and in-ear monitoring devices, 2007-07.

11. Rohde \& Schwarz (2002): Audio Analyzer UPL/UPL16/UPL66, Betriebshandbuch. Munich. 


\section{Authors}

\section{Bernhard Auinger}

received the master's degree in electrical engineering (Dipl.-Ing.) in 2004 and the Dr. techn. degree with distinction in 2015, both from Graz University of Technology, Austria. From 2011 to 2015 he was involved in theoretical investigations for wireless communications and on test procedures for MIMO enabled user equipment using LTE, which was a cooperation between the Institute of Microwave and Photonic Engineering, Graz University of Technology and the company Rohde \& Schwarz, Munich, Germany. From 2005 to 2011 he initiated and led the electromagnetic compatibility group for automotive ICS at Philips Semiconductors and NXP Semiconductors. During his studies he was engaged in the comet mission ROMAP/ROSETTA of the European Space Agency (ESA). Currently, he is researcher at the Institute of Electronics, Graz University of Technology and investigates new semiconductor technologies for increasing the efficiency, shrinking the unit size and reducing emissions of welding machines and switched power converters for solar power.

\section{Philipp Freidl}

was born in Graz, Austria, in 1987. He received the diploma degree in electrical engineering from Graz University of Technology, Graz, Austria, in 2013. During his studies and master thesis, he worked on the development of ultra-wideband antennas with double and circular polarization properties. Since April 2013, he has been with the Institute of Microwave and Photonic Engineering, Graz University of Technology, Graz, Austria, as a University Project Assistant and Ph.D. student. He is currently involved in the definition and development of hardware components and system design for mm-wave identification.

\section{Michael Gadringer}

received the Dipl.-Ing. and the Dr. techn. degrees from the Vienna University of Technology, Austria, in 2002 and 2012, respectively. Since 2010 he has been University Assistant at the Institute of Microwave and Photonic Engineering at the Graz University of Technology. During his studies he was involved in the design of analog and digital linearization systems for power amplifiers and with the behavioral modeling of microwave circuits. His current research activities focus on the design and linearization of broadband microwave and mm-wave communication systems as well as on measurement techniques and de-embedding. He has co-edited the book "RF Power Amplifier Behavioral Modeling", published by Cambridge University Press.

\section{Christian Glawan}

received his master's degree (Dipl.-Ing.) in computer science from the Vienna University of Technology, Austria, in 2000. From 1999 to 2000 he was into designing and developing parts of the timetriggered hard realtime systems at TTTech AG Vienna. In 2000 he joined the technical planning department of the national Austrian public broadcaster (ORF). There he has been responsible for designing, tendering, and implementing central systems, e.g. TV continuity and automation systems. Currently, he is investigating low power RF production equipment in consideration of shrinking available RF spectrum and increasing production demands.

\section{Gunter Winkler}

was born in 1959. He studied electrical engineering at the Graz University of Technology, Austria. Since 1986 he has been working at the Institute of Electronics, Graz University of Technology, in the fields of Electromagnetic Compatibility (EMC) on system and integrated circuit (IC) level as well as on analog digital converters with high resolution. He is assistant professor and co-leader of the institute and cooperates with the IEEE EMC-Chapter Austria.

\section{Wolfgang Bösch}

joined the Graz University of Technology, Austria, in March 2010, in order to establish a new Institute of Microwave and Photonic Engineering. Prior he was the CTO of the Advanced Digital Institute in the UK, a not for profit organization to promote research activities. He was also the Director of Business and Technology Integration of RFMD UK. For almost ten years he was with Filtronic plc as CTO of Filtronic Integrated Products and Director of the Global Technology Group. Prior to joining Filtronic, he held positions in the European Space Agency (ESA) working on amplifier linearization techniques, MPR-Teltech in Canada working on MMIC technology projects and the Corporate R\&D group of M/A-COM in Boston where he worked on advanced topologies for high efficiency power amplifiers. For four years he was with DaimlerChrysler Aerospace in Germany, working on T/R Modules for airborne radar. Dr. Bösch received his engineering degrees from the Vienna University of Technology and the Graz University of Technology, Austria. He finalized his MBA with distinction at Bradford University School of Management in 2004. He is a Fellow of the IEEE and a Fellow of the IET. He published more than 50 papers and holds 4 patents. He was a Non-Executive Director of Diamond Microwave Devices (DMD) and is currently a Non-Executive Director of the Advanced Digital Institute (ADI) and VIPER-RF company. 